\title{
Analysis of Maternal Deaths in Suburban of Dakar, Senegal
}

\author{
Abdoul Aziz Diouf ${ }^{*}$, Omar Gassama², Moussa Diallo1, Mohamed T. Diadhiou², \\ Simon Birame Ndour ${ }^{1}$, Mamour Gueye ${ }^{3}$, Alassane Diouf ${ }^{1}$ \\ ${ }^{1}$ Pikine National Hospital, Thiaroye, Dakar, Senegal \\ ${ }^{2}$ Aristide Le Dantec Teatching Hospital, Dakar, Senegal \\ ${ }^{3}$ Phillipe Maguilen Senghor Hospital, Yoff, Dakar, Senegal \\ Email: *dizzefr@yahoo.fr
}

How to cite this paper: Diouf, A.A., Gassama, O., Diallo, M., Diadhiou, M.T., Ndour, S.B., Gueye, M. and Diouf, A. (2021) Analysis of Maternal Deaths in Suburban of Dakar, Senegal. Open Journal of Obstetrics and Gynecology, 11, 523-528.

https://doi.org/10.4236/ojog.2021.115049

Received: March 28, 2021

Accepted: May 15, 2021

Published: May 18, 2021

Copyright $\odot 2021$ by author(s) and Scientific Research Publishing Inc. This work is licensed under the Creative Commons Attribution International License (CC BY 4.0).

http://creativecommons.org/licenses/by/4.0/

\begin{abstract}
Objective: Maternal mortality remains a major concern in developing countries. This survey aims to suggest strategic plans that would help decrease maternal and perinatal mortality in the suburbs. It is a descriptive study that shows the different causes of maternal deaths during pregnancy and puerperium period. Methods: It is a retrospective descriptive study done between January $1^{\text {st }} 2016$ and the $31^{\text {st }}$ of December 2018. We have collected information on all deaths due to mortality issues in Five (5) maternity clinics around Dakar. The record shows that teach centre have an average of 4000 deliveries per year. The data collected from the hospital records were inputted using Sphinx software (version 5). These data were analysed using Epi Info software (version 3.5). After analysing these data, recommendations were made to minimize the different causes of maternal deaths. Results: We recorded 154 maternal deaths out of 32,420 live births. The direct causes of maternal deaths were a result of preeclampsia and its complications (31.2\%), postpartum haemorrhage $(24.7 \%)$, abruption placentae $(20.8 \%)$ and obstructed labour (7.8\%). The indirect causes were mainly sickle cell disease (1.3\%), heart disease $(1.3 \%)$ and gynaecological cancers (1.3\%). Maternal deaths were also associated with fetal loss in $47.4 \%$ of 153 maternal deaths, need for blood transfusion 59\% while none of the reference structures in the suburbs of Dakar has a blood bank; with a need for admission in intensive care unit was noted as $40 \%$. Conclusion: Thus, preeclampsia and its complications are the leading cause of maternal deaths in suburban settings. Timely availability of resuscitation units and liable blood products could drastically reduce maternal deaths from direct obstetric complications.
\end{abstract}

\section{Keywords}

Maternal Mortality, Preeclampsia, Haemorrhage, Emergency Obstetric and 


\section{Introduction}

Maternal and perinatal mortality in low-density areas can be a challenge for some African cities. Dakar is no exception even though there is a drop in the maternal mortality rate in Senegal (236 deaths from maternal births per 100,000 live births) [1]. To be accurate, we did some analysis to know the causes of maternal deaths in the suburbs. A descriptive approach helped us make some recommendations that can aid existing strategies to improve on maternal and perinatal health.

\section{Materials and Methods}

Suburban of Senegal-Dakar is divided into three (3) sectors which encompass $63.4 \%$ of the regional population of Dakar with 2,434,045 inhabitants. These sectors contain three (3) obstetric referral structures (Pikine National Hospital, Youssou Mbargane Diop hospital and King Baudouin Hospital). We conducted a multi-centre of descriptive and cross-sectional study of all cases of maternal death recorded over the past three years (that is from 2016, 2017 and 2018). Each maternal death had been examined to know the root cause. We also studied the socio-demographic characteristics of the patients, the delivery dates and the causes of each death, from the available data in the hospital records. Data were also inputted and analyzed using Sphinx (version 5) and Epi Info software (version 3.5). This work has received the approval of the ethics committee of our institution.

\section{Results}

\subsection{General Characteristics and Causes of Maternal Deaths}

The maternal mortality rates were 475 deaths per 100,000 births (154 maternal deaths out of 32,420 live births). Accounting to the study, the minimum age of decreased due to maternal death was 18 years, with an average of 31 years and a maximum of 45 years.

The average parity was 2.9 with a predominance of multiparas (38\%). Prenatal follow-up were of poor quality which resulted in $71.5 \%$ of the cases and $77 \%$ of patient were discharged in these place (Table 1). The record shown that the main mode of delivery was caesarean section (107 cases or 70\%). Majority of the deaths occurred in the postpartum period and the average time between childbirth and death was 40 hours.

The median was 12 hours and $77 \%$ of these patients died within 24 hours. The direct causes of maternal death (Table 2) were as a result of preeclampsia (31.2\%), postpartum haemorrhage (24.7\%), abruption placentae (20.8\%) and dystocia (7.8\%). The indirect causes were sickle cell disease (1.3\%), heart disease $(1.3 \%)$ 
Table 1. Distribution of deceased women according to general characteristics $(n=154)$.

\begin{tabular}{|c|c|c|}
\hline & Number & Percent \\
\hline \multicolumn{3}{|l|}{ Mode of admission } \\
\hline Evacuated & 119 & $77 \%$ \\
\hline Coming by herself & 35 & $28.3 \%$ \\
\hline \multicolumn{3}{|l|}{ Age groups } \\
\hline Age $<20$ years & 5 & $3.2 \%$ \\
\hline Age between 20 - 34 years & 104 & $67.5 \%$ \\
\hline Age $>34$ years & 45 & $29.3 \%$ \\
\hline \multicolumn{3}{|l|}{ Departmental addresses } \\
\hline Département of Pikine & 100 & $65 \%$ \\
\hline Département of Rufisque & 26 & $17 \%$ \\
\hline Département of Guédiawaye & 14 & $9 \%$ \\
\hline Other départements & 14 & $9 \%$ \\
\hline \multicolumn{3}{|l|}{ Period of death } \\
\hline During pregnancy & 6 & $3.9 \%$ \\
\hline During childbirth & 10 & $6.4 \%$ \\
\hline In the immediate postpartum & 98 & $63.7 \%$ \\
\hline In the late postpartum (after 48 hours) & 40 & $26 \%$ \\
\hline \multicolumn{3}{|l|}{ Becoming a child } \\
\hline Alive & 81 & 52.6 \\
\hline Stillborn fresh & 64 & 41.6 \\
\hline Macerated stillborn & 3 & 1.9 \\
\hline Discontinuation in the first trimester & 6 & 3.9 \\
\hline
\end{tabular}

Table 2. Distribution of maternal deaths by cause $(n=154)$.

\begin{tabular}{lcc}
\hline \multicolumn{1}{c}{ Causes of maternal death } & Number & Percentage \\
\hline Direct causes & 48 & \\
Preeclampsia/eclampsia & 38 & $31.2 \%$ \\
Immediate postpartum haemorrhage & 32 & $24.7 \%$ \\
Abruptio placentae & 12 & $20.8 \%$ \\
Dystocia/uterine rupture & 4 & $7.8 \%$ \\
Complications of abortion & 3 & $2.6 \%$ \\
Pulmonary embolism & 3 & $1.9 \%$ \\
Puerperium infections & 1 & $1.9 \%$ \\
Ectopic pregnancy & 1 & $0.6 \%$ \\
Pregnancy vomiting & 1 & $0.6 \%$ \\
Anesthetic complications & 2 & $0.6 \%$ \\
Placenta previa & & $1.3 \%$ \\
\hline
\end{tabular}




\section{Continued}

\begin{tabular}{lcc}
\hline Indirect causes & & \\
Ovarian tumor & 2 & $1.3 \%$ \\
Pregnancy vomiting & 1 & $0.6 \%$ \\
Heart disease and pregnancy & 2 & $1.3 \%$ \\
Homozygous sickle cell disease & 2 & $1.3 \%$ \\
Hyperthyroidism & 1 & $0.6 \%$ \\
Adrenal insufficiency & 1 & $0.6 \%$ \\
Liver cancer & 1 & $0.6 \%$ \\
Total & 154 & $100 \%$ \\
\hline
\end{tabular}

and gynaecological cancers (1.3\%). Maternal deaths were also associated with fetal loss in $47.4 \%$ of the cases.

\subsection{Conclusion of Maternal Death Audits}

From the facts listed above, we concluded that only $30 \%$ of deaths can be categorized as inevitable as they resulted from unforeseeable complications or due to chronic diseases. Other deaths could have been avoided if these patients were diagnosed at an early stage and therapeutic procedures carried out as soon as possible. We found that the major part of these complications (77\%) had occurred in peripheral structures managed only by midwives with few therapeutic means at their disposal, whereas an emergency caesarean need were effective in $61.6 \%$ of these cases. Due to these situations, $40 \%$ of them were hospitalized in an intensive care unit (Table 3) and a need for blood transfusion was necessary in $59 \%$ of the cases.

Table 3. Distribution of maternal deaths according to the unmet need for blood transfusion and hospitalization $(\mathrm{n}=154)$.

\begin{tabular}{lcc}
\hline \multicolumn{1}{c}{ Causes of maternal death } & Number & Percentage \\
\hline Need for transfusion & 38 & \\
Immediate postpartum haemorrhage & 32 & $24.7 \%$ \\
Abruptio placentae & 12 & $20.8 \%$ \\
Dystocia/uterine rupture & 1 & $7.8 \%$ \\
Ectopic pregnancy & 2 & $0.6 \%$ \\
Placenta previa & 4 & $1.3 \%$ \\
Complications of abortion & & $2.6 \%$ \\
Need for hospitalization in intensive care & 48 & \\
Preeclampsia/eclampsia & 3 & $31.2 \%$ \\
Pulmonary embolism & 1 & $1.9 \%$ \\
Anesthetic complications & 2 & $0.6 \%$ \\
Heart disease and pregnancy & 2 & $1.3 \%$ \\
Homozygous sickle cell disease & & $1.3 \%$ \\
\hline
\end{tabular}




\section{Continued}

$\begin{array}{lcc}\text { Hyperthyroidism } & 1 & 0.6 \% \\ \text { Adrenal insufficiency } & 1 & 0.6 \% \\ \text { Pregnancy vomiting } & 1 & 0.6 \% \\ \text { Puerperal infections } & 3 & 1.9 \% \\ \text { Other } & & \\ \text { Ovarian tumor } & 2 & 1.3 \% \\ \text { Liver cancer } & 1 & 0.6 \% \\ \text { Total } & 154 & 100 \%\end{array}$

Thus, maternal deaths were particularly as a result of lack of labile blood products, fewer resuscitation units, and lack of experienced midwives faced with uncontrollable situations.

\section{Discussion}

\subsection{Causes of Death}

The causes of maternal deaths were mainly haemorrhages (44\%) and preeclampsia (36\%) and these results were identical to those found by one of our experienced medical practitioners [2], and others from the sub-regions [3] [4] [5] [6].

However, considering the abruption placentae (13.7\%) as a complication of preeclampsia, we came to conclude that the latter is the leading cause of maternal deaths from our study. Rafanomezantsoa [7] in Madagascar and Foumane in Cameroon [3] reported the same findings.

Another issue concerning obstructed labour and uterine rupture was cited in this section. Uterine rupture and obstructed labour are two very distinct direct obstetric complications, whereas in many cases of uterine rupture are secondary to obstructed labour. Taking this into account, then obstructed labour should come third among the causes of maternal deaths.

Deaths linked to an ectopic pregnancy are on the decline; this observation can be explained by the popularization of ultrasound. The diagnosis and treatment of patients as a result of complication of abortions also contribute as part of the causes of maternal death. We can say that they have regressed increase in contraceptive prevalence, but also with the new methods of abortion, are less dangerous, using misoprostol.

\subsection{Avoidability of Maternal Deaths}

Maternal death can occur at any time during pregnancy or after childbirth. Childbirth is by far the most dangerous period; however, this maternal death is often unpredictable and need easy access to emergency obstetric care in the event of pregnancy complications.

Under this subject, many shortcomings are noted in under developed countries. Qualified medical personnel are in short supply in our societies, not to 
mention the lack of continuous training to improve on skills. Furthermore, maternity hospitals that do not have a blood bank might find it difficult to treat severe anaemia within a short period of time.

We should also take into consideration the inadequate maternal resuscitation units in suburbs. Facts have shown that the need for hospitalization of these patients in an intensive care unit was $93 \%$ and transfusion of labile blood products were $52 \%$ of the cases.

The availability of labile blood products can be a result of several reasons like the construction of blood transfusion centres in each referral structure, to facilitate and enhance blood donation.

\subsection{Implications for Practice and Research}

The causes of death in the nursery schools, in the suburbs of Dakar are mainly represented by preeclampsia and haemorrhages.

Construction of a blood bank and resuscitation units in referral structures could considerably reduce maternal deaths.

\section{Conclusion}

To minimize this situation, there is definitely a need to establish resuscitation units in these areas and a labile blood product near the reference structures.

\section{Conflicts of Interest}

The authors declare no conflicts of interest regarding the publication of this paper.

\section{References}

[1] Final Report of Demographic and Health Survey 2017

[2] Biaye, B., et al. (2019) Maternal Mortality in a Maternity Ward at a Regional Hospital Center in Southern Senegal. International Research Journal of Obstetrics and Gynecology, 2, 10.

[3] Fomulu, F.J., Ngassa, P.N., Nong, T., Nana, P. and Nkwabong, E. (2013) Mortalité maternelle à la Maternité du Centre Hospitalier et Universitaire de Yaoundé, Cameroun: étude rétrospective de 5 ans (2002 à 2006). Health Sciences and Diseases, 10, No. 1.

[4] Graham, W.J., Fitzmaurice, A.E., Bell, J.S., and Cairns, J.A. (2004) The Familial Technique for Linking Maternal Death with Poverty. The Lancet, 363, 23-27. https://doi.org/10.1016/S0140-6736(03)15165-3

[5] Bah, A.O., Diallo, M.H., Conde, A.M. and Keita, N. (2011) Hypertension artérielle et grossesse: mortalité maternelle et périnatale. Médecine d Afrique Noire, 48, 461-464.

[6] Möller, B., Kabukoba, J., Kavishe, F., Gebre-Medhin, M., Meirik, O., et al. (1989) A Prospective Area-Based Study of the Outcome of Pregnancy in Rural Tanzania. Upsala Journal of Medical Sciences, 94, 101-109. https://doi.org/10.3109/03009738909179253

[7] Rafanomezantsoa, T.A., HariolyNirina, M.O.J., Fenomanana, S., Ramarokoto, M.P.M., Andrianampanalinarivo, H.R, Raveloson, N.E. (2014) Maternal Mortalities Seen at the University Hospital of Gynecology-Obstetrics of Befelatanana: 20112013. Med. Afr. Noire, 6112, 622-628. 